\title{
Urban Air Quality and Sustainable Development
}

\author{
M. Lazaridis • K. Aravosis
}

Received: 15 April 2008 / Accepted: 20 June 2008 / Published online: 2 December 2008

(C) Springer Science + Business Media B.V. 2008

\section{Preface}

Measurements and model simulations of air pollution in urban agglomerations and industrial places have shown high concentrations of gaseous and particulate matter pollutants such as photochemical gaseous pollutants and particulate matter. The world's urban population increased over the past 50 years with an average rate of $2.7 \%$ year $^{-1}$. By contrast, the total world population increased with an average rate of only $1.8 \%$ year $^{-1}$. This illustrates the increasing global importance of urban agglomerations and industrial activities, thus their growing significance for the world's air quality and climate problems. Air quality degradation in urban agglomerations and industrial sites has significant effects to human health leading to increased morbidity and mortality, to urban and regional air quality degradation and consequently to the earth's climate.

The sustainable development is the second focus of the current special issue. The usual assumption is that it is difficult to achieve the growth of enterprise in an environmentally friendly manner. This paradigm

M. Lazaridis $(\bowtie)$

Department of Environmental Engineering,

Technical University of Crete,

Polytechneioupolis,

73100 Chania, Greece

e-mail: lazaridi@mred.tuc.gr

K. Aravosis

School of Mechanical Engineering, Sector of Industrial

Engineering and Operations Research,

National Technical University of Athens,

Polytechneioupolis, Zografos,

17454 Athens, Greece usually associated with developed countries is now affecting all other regions of the globe. The main question is if the development of enterprise is compatible with environmental protection. An important research area is that which deals with development and growth finding its way, in accordance with the principles of sustainability, considering social and environmental impacts as well.

The present special issue of the Journal Water Air and Soil Pollution-Focus contains 14 selected papers that were presented at the 1st International Conference on Environmental Management, Engineering, Planning and Economics (CEMEPE), which was held together with a special conference of the Society for Ecotoxicology and Environmental Safety (SECOTOX) and took place on the Greek island of Skiathos from June 24 to 28, 2007.

The papers presented in the Conference covered a wide range of scientific disciplines related to environment. The guest editors decided to present a special issue that focuses mainly on urban air quality and sustainable development. The papers study the air quality in urban and industrial sites with measurements and modeling tools and the related health effects, as well as papers that deal with important factors that lead to sustainable development.

The papers presented here are based on those given at the Conference but have been subjected to peer review by at least two independent referees. The 14 papers that successfully passed the review process are presented here.

We are grateful to the reviewers for their careful and objective evaluation of the submitted papers and the Organizing Committee of the CEMEPE Conference. 